\title{
Wind-induced Vibration Optimal Control for Long Span Transmission Tower-line System
}

\author{
Li Tian*,1, Qian Wang ${ }^{1}$, Qiqi $\mathrm{Yu}^{1}$ and Nuwen $\mathrm{Xu}^{2}$ \\ ${ }^{1}$ School of Civil and Hydraulic Engineering, Shandong University, Jinan, Shandong, 250061, China \\ ${ }^{2}$ College of Water Resources and Hydropower, Sichuan University, Chengdu, Sichuan, 610065, China
}

\begin{abstract}
In this paper, tuned mass dampers with optimal parameters for long span transmission tower-line system are investigated. Equations of motion for a structure-TMD system are derived, and the parameters of TMD, stiffness and damping are optimized, respectively. According to a real project, three-dimensional finite element models of both transmission tower and transmission tower-line system are created and their vibration performances are analyzed using SAP2000 software, respectively. Wind load time history is simulated based on wind theory. Using numerical simulation, vibration control with optimal tuned mass damper installed in transmission tower-line system is carried out. Time history curves and the maximum responses of system without and with tuned mass damper under wind excitation are analyzed and discussed. The results show that the optimal tuned mass damper could effectively decrease the wind-induced response of long span transmission tower-line system.
\end{abstract}

Keywords: Long span transmission tower-line system, tuned mass damper, Wind-induced optimal vibration control, numerical simulation.

\section{INTRODUCTION}

The long span transmission tower-line system is a kind of power facility of great significance for such developing country as China. Comparing to usual overhead transmission line structures, long span transmission tower-line system has some unique characteristics: with high-rise tower, large-span and huge massive structural flexibility. these peculiarities implicate its sensitivity to wind load and more probability of destruction under wind excitation [1]. Wind-induced destructions of transmission lines usually occur in the past coupled of decades [2]. For example, during 1998 wind vibration, four transmission towers collapsed in the east China. In 2002 wind vibration, many transmission lines were damaged because of strong wind in Liaoning province of China. In 2005 wind vibration transmission towers damaged seriously in Jiangsu province of China. A few domestic and foreign researchers have studied the vibration control of transmission tower-line system in recent years. Zheng et al. [3] developed analytical method of transmission tower-line system incorporated with passive friction dampers. Tian et al. [4] investigates tuned liquid damper for transmission tower.

In order to ensure the reliability of transmission towerline system, wind-induced vibration control should be considered as an important project. Equations of motion for a structure-TMD system are derived, and the optimization of TMD parameters is obtained. Three-dimensional finite

*Address correspondence to this author at the School of Civil and Hydraulic Engineering, Shandong University, Jinan, Shandong, 250061, China; Tel:+86 531-88396182; Fax:+86 531-88392843;

E-mail: tianl-007@163.com element model of both transmission tower and transmission tower-line system is established. Wind load time history is simulated based on wind theory. Vibration control with optimal tuned mass damper is carried out by numerical simulation. The results of system without and with optimal TMD are compared and discussed.

\section{EQUATIONS OF MOTION FOR A STRUCTURE- TMD SYSTEM}

As shown in Fig. (1), the tuned mass damper and structure are assumed to vibrate with the same frequency. With the opposite movement exerted by tuned mass damper to structure, the purpose of vibration control is obtained. Assume that a structure can be modeled as a single degree of

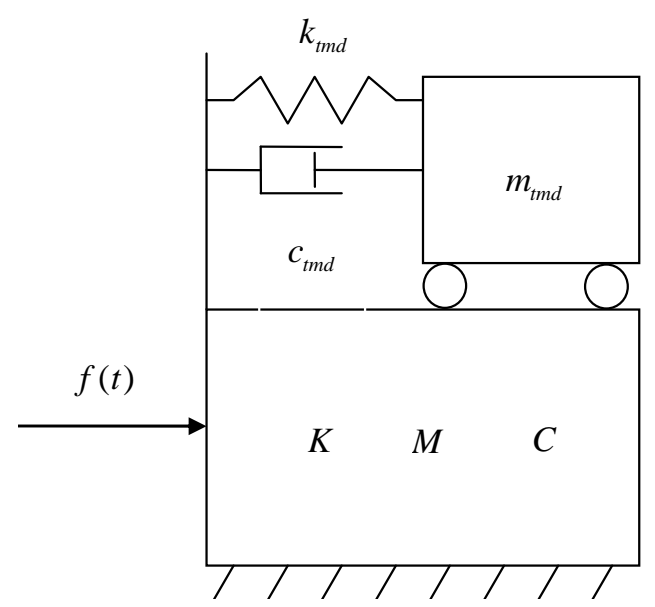

Fig. (1). Schematic structure with tuned mass damper. 
freedom system, and a tuned mass damper is installed, reducing vibration system can be seen from Fig. (1). The equation of motion of the structure for the TMD control can be expressed as

$$
\begin{aligned}
& \mathbf{M} \ddot{\mathbf{x}}+\mathbf{C} \dot{x}+\mathbf{K} x-\left(c_{t m d} \dot{x}_{t m d}+k_{t m d} x_{t m d}\right)=F(t) \\
& m_{t m d}\left(\ddot{x}_{t m d}+\ddot{x}\right)+c_{t m d} \dot{x}_{t m d}+k_{t m d} x_{t m d}=0
\end{aligned}
$$

where, $M 、 C 、 K$ are the mass, damping and stiffness matrix for the structure, respectively. $x 、 \dot{x} 、 \ddot{x}$ are the displacement, velocity and acceleration vectors for the structure, respectively. $F(t)$ is the wind-induced loading vector. $x_{t m d}, \dot{x}_{t m d}$ and $\ddot{x}_{t m d}$ are the displacement, velocity and acceleration for the TMD, respectively. $m_{t m d}, c_{t m d}$ and $k_{t m d}$ are the mass, damping and stiffness for the TMD, respectively.

\section{OPTIMAL PARAMETER OF TMD}

The stiffness $k_{t m d}$ and damping $c_{t m d}$ of TMD to structure are generally acknowledged as two parameters of great importance, which can be expressed as following equations

$$
\begin{aligned}
& k_{t m d}=m_{t m d} \omega_{t m d}^{2} \\
& c_{t m d}=2 m_{t m d} \omega_{t m d} \xi
\end{aligned}
$$

An appropriate choice of these two parameters leads to success reducing wind vibration. The purpose of reducing wind-vibration is accomplished by the opposite movement exerted by TMD, this requests that tuned state, $\omega_{\text {tmd }}=\omega_{\text {structure }}$, is able to achieved. However, tuned state is difficultly fulfilled in reality, because $\omega_{\text {structure }}$ was changed after fixing TMD to structure (the total mass of structure was increased).

With the consideration of the poblems discussed above, an access to optimal parameter of TMD was given by Den Hartog [5]. According to his theory, two optimal coefficients are introduced to take the mass variation of structure into account, which can be expressed as

$$
\begin{aligned}
& \alpha_{\text {opt }}=\frac{1}{1+\mu} \\
& \xi_{\text {opt }}=\sqrt{\frac{3 \mu}{8(1+\mu)}}
\end{aligned}
$$

where, $\mu$ is the mass ratio of TMD to structure, in this paper $\mu=0.01$.

In conclusion, the optimal parameter of TMD, $k_{\text {opt }}$ and $c_{\text {opt }}$ can be expressed as

$$
\begin{aligned}
& k_{o p t}=m_{t m d} \omega_{o p t}^{2}=m_{\text {tmd }}\left(\alpha_{\text {opt }} \omega_{\text {structure }}\right)^{2} \\
& c_{\text {opt }}=2 m_{\text {tmd }} \omega_{t m d} \xi_{\text {opt }}
\end{aligned}
$$

\section{LONG-SPAN TRANSMISSION TOWER-LINE SYS- TEM MODEL}

A transmission tower and tower-line system based on a real electric power transmission project in north of China are established, respectively. The size of transmission tower is shown in Fig. (2). The tower is $122 \mathrm{~m}$ high, and the weight of the tower is approximately 140.4 t. As shown in Fig. (3), three-dimension finite element tower according to practical project is established. A finite-element computer program SAP2000 is selected to establish the model. The structural members of the tower are made of steel tube and angle steel. The tower is modeled by 1148 space beam members and 438 nodes, and the connections of members are rigid, and the base points of the tower are assumed fixed. The first three vibration mode shapes in $\mathrm{X}$ direction are illustrated in Fig. (4), and the frequencies of free vibration corresponding to the first three modes of the tower in $\mathrm{X}$ direction are found to be $0.789,0.340$ and $0.299 \mathrm{~Hz}$.

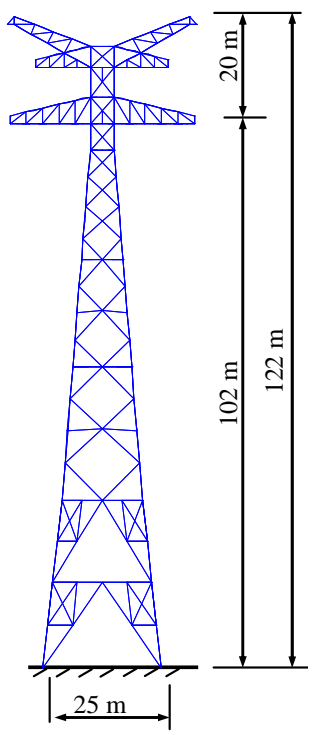

Fig. (2). Size of tower.

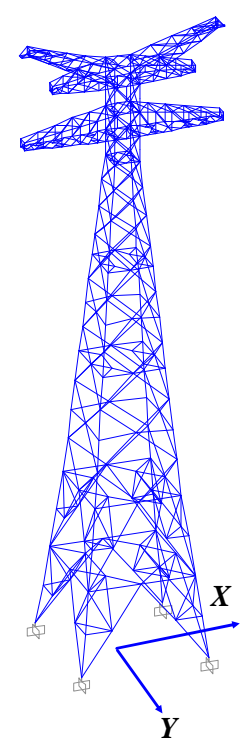

Fig. (3). Finite model. 
The size of transmission tower-line system is shown in Fig. (5). It is composed of two towers and three spans of transmission lines, and the span between two towers is $1118 \mathrm{~m}$. The ground lines and conductors are simulated by the SAP2000 cable members. Transmission lines are made up of two ground lines in the top layer and six conductors. Fig. (6). illustrates the first mode of tower in $\mathrm{X}$ direction under tower-line system, and its frequency is found to be $1.224 \mathrm{~Hz}$.

\section{WIND LOAD TIME HISTORY SIMULATION}

It is well known that transmission tower-line system is a typical high-rise structure. because the height of tower is so high, the vertical variation of wind velocity spectrum should be considered. The Kaimal spectrum considers that the wind velocity spectrum varies along height [6]. So Kaimal spectrum and Harmony superposition method [7] are adopted to simulate time history of fluctuating wind velocity and wind load. Mean wind speed at $10 \mathrm{~m}$ height is assumed to be 30 $\mathrm{m} / \mathrm{s}$.

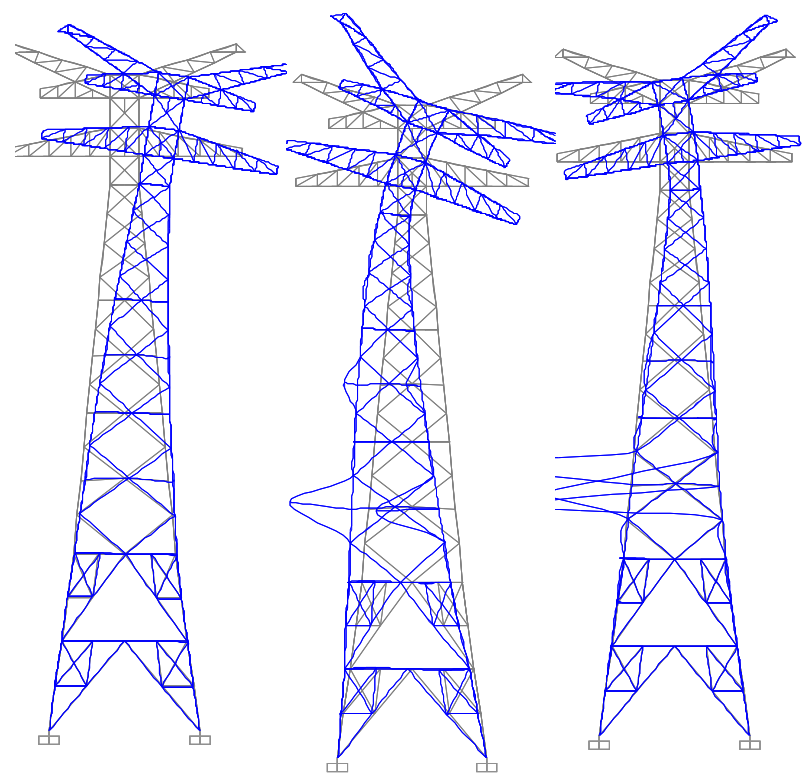

Fig. (4). The first three modes in $\mathrm{X}$ direction.

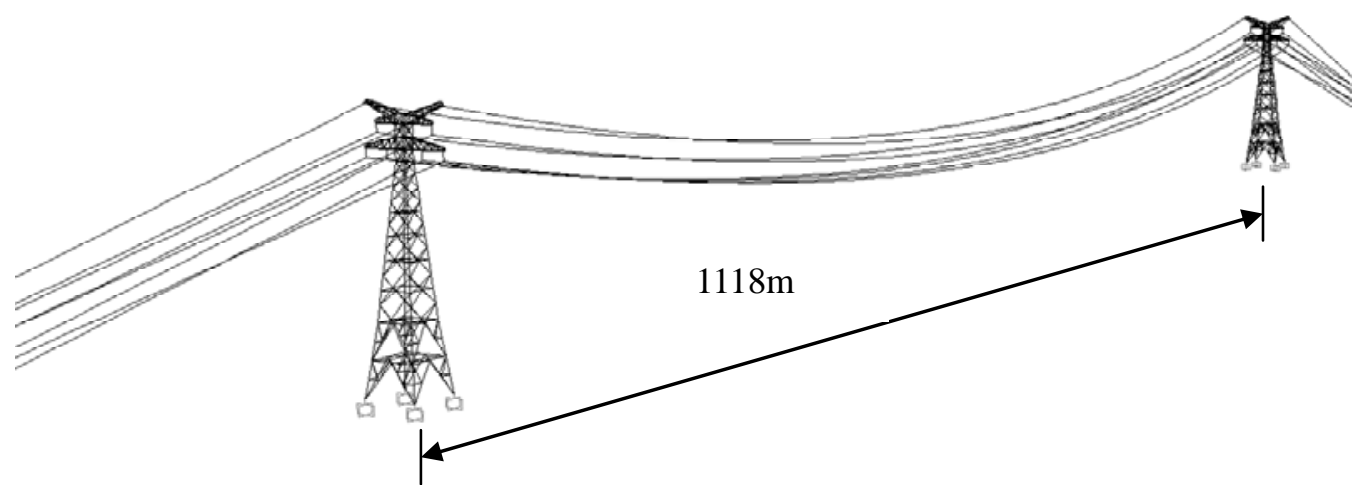

Fig. (5). Three dimensional finite element model of transmission tower-line system.

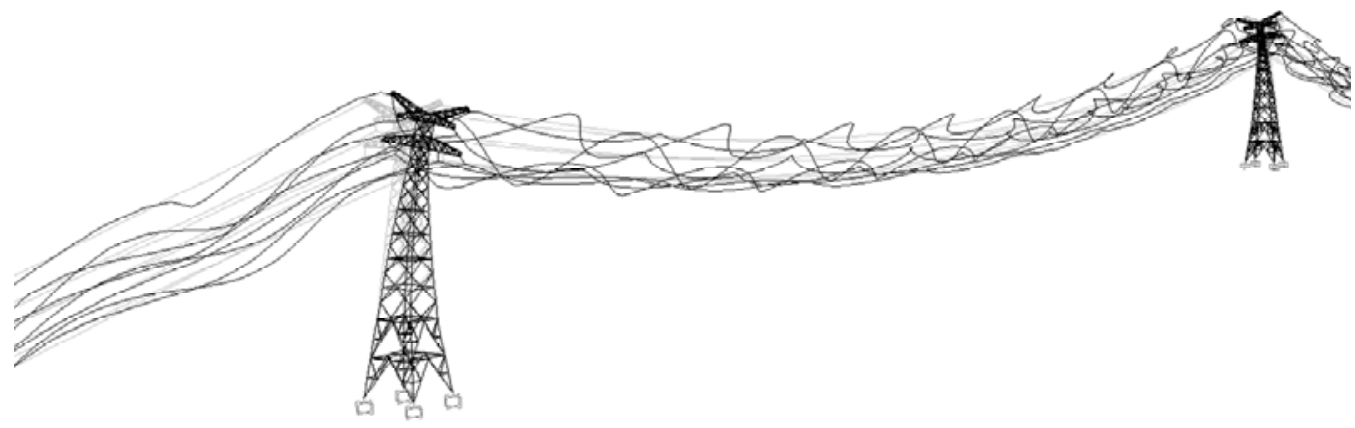

Fig. (6). The first mode of tower in X direction of transmission tower-line system. 


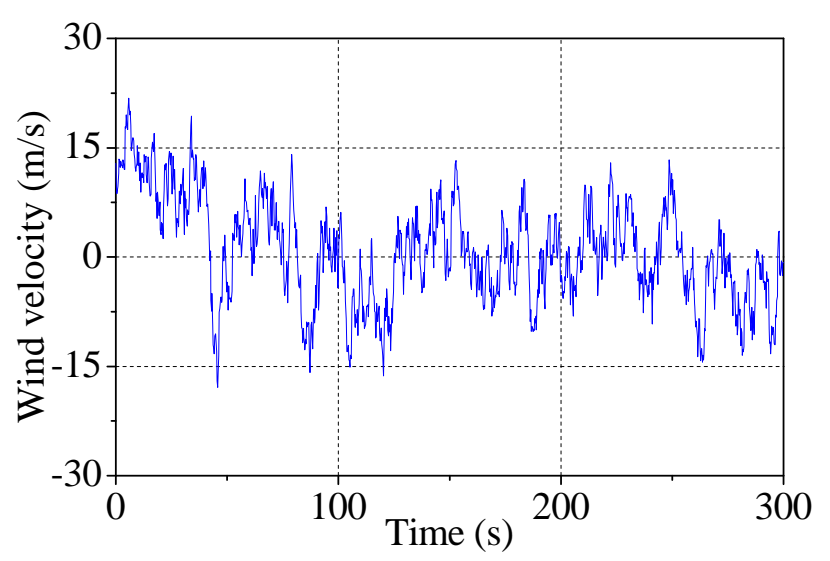

Fig. (7). Wind speed time-history.

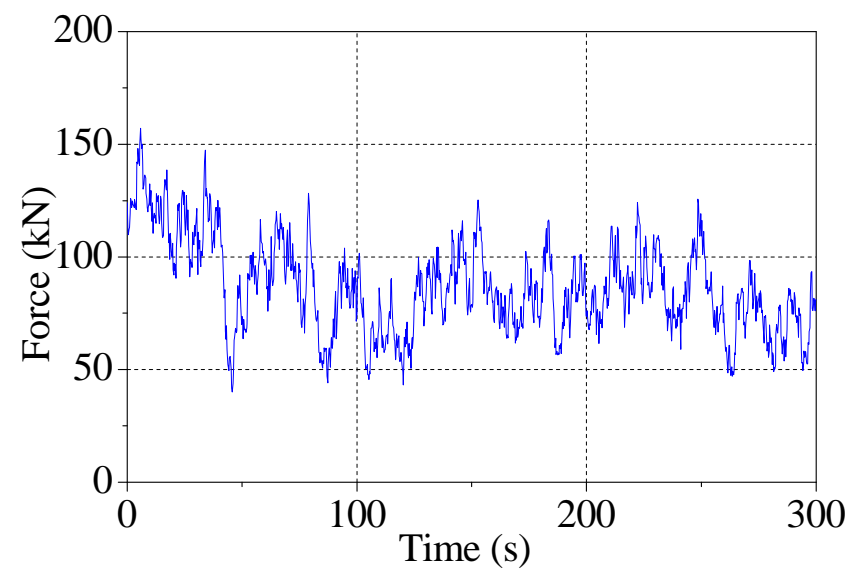

Fig. (8). Wind load time-history.

Based on above method, wind speed and wind load time histories are generated according to simulation program. The wind speed and load time history of the top node of transmission tower of tower-line system are shown in Figs. (7, 8), respectively.

\section{NUMERICAL ANALYSIS AND DISCUSSION}

The transition tower line system shown in Fig. (5) is used in numerical simulation analysis. Proportional damping is adopted in tower line system, since the system is composed of both cable and tower. The damping ratio of ground and conductors is $1 \%$ and the damping ratio of the tower is assumed to be $2 \%$. The wind load time history obtained in above work is exerted on specified position of tower line system. The Hilber-Hughes-Taylor method is applied in numerical integration. Based on SAP2000 nonlinear time history analysis, the tower-line system with and without optimal TMD is studied, respectively. The response contains the acceleration and displacement of top node, the axial force of bottom element and the maximum axial force of a series of elements along height.

In this paper, vibration decreasing ratio is introduced to investigate the effect of optimal TMD. It can be defined as:
$\delta=\frac{R_{0}-R_{1}}{R_{0}} \times 100 \%$

where, $\delta$ is vibration decreasing ratio. $R_{0}$ is the maximum response of structure without optimal TMD, and $R_{1}$ is the maximum response of structure with optimal TMD.

Figs. $(9,10)$ illustrate the comparison of acceleration and displacement time history curve of top node with and without optimal TMD. It can be seen from the figures that optimal TMD can reduce the acceleration and displacement of top node. The displacement response of tower with optimal TMD curve is smaller than it without control and the decreasing ratio is about $7.6 \%$. Fig. (11) shows the comparison of axial force time history at bottom element. It can be seen that the axial force is significantly decreased by optimal TMD with the decreasing ratio is around 12.9\%. Fig. (12) demonstrates two curves of maximum axial force of a series of vertical tower elements along the height of tower, the values in optimal TMD curve at any height is all smaller than those in curve without control. It also can be seen form the

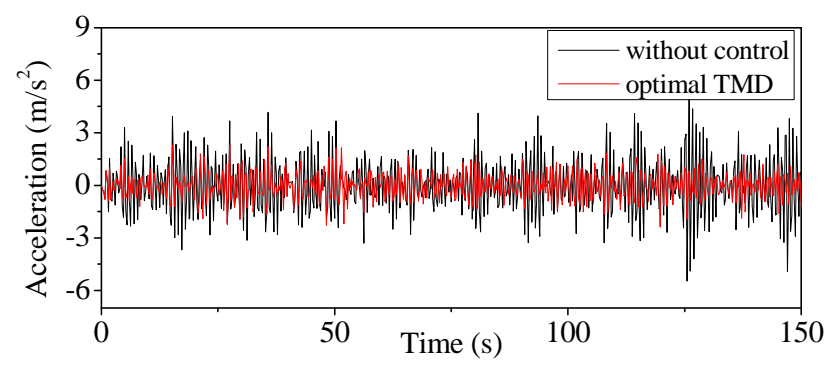

Fig. (9). Comparison of acceleration time history.

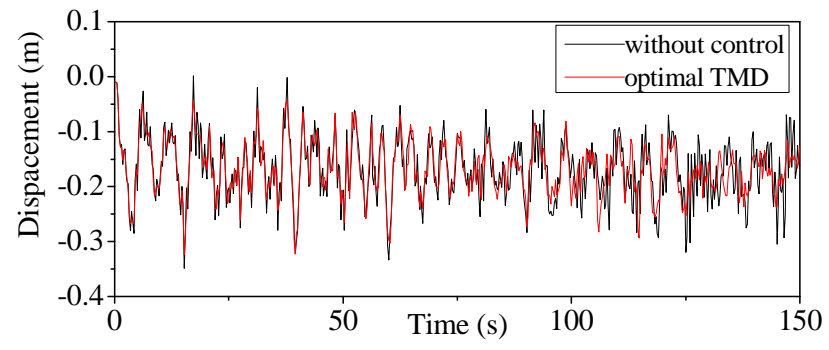

Fig. (10). Comparison of displacement time history.

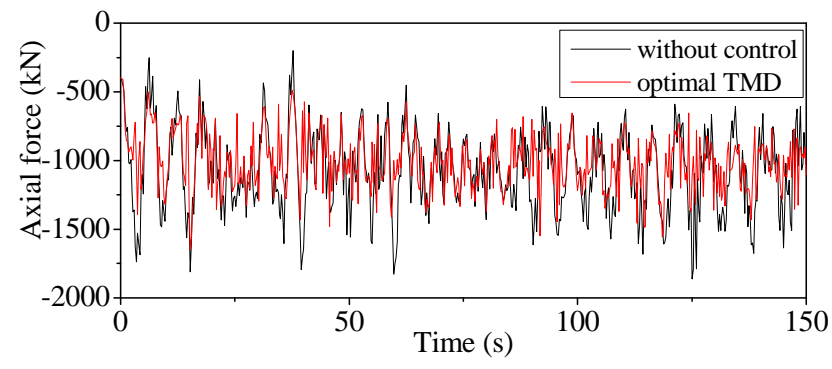

Fig. (11). Comparison of axial force time history. 


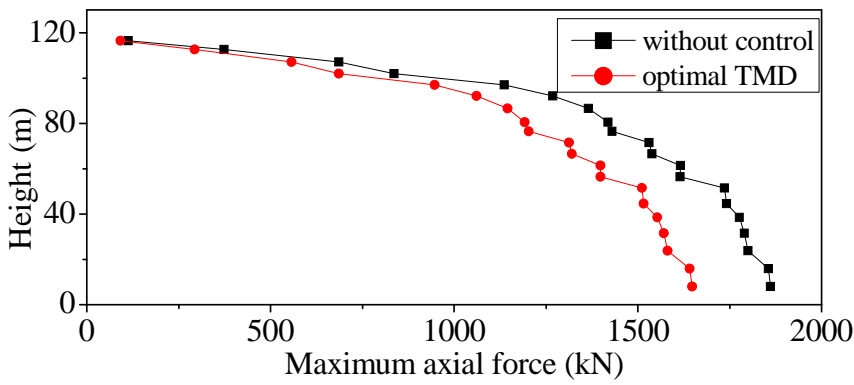

Fig. (12). Comparison of maximum axial force.

figure that with the growth of height, the optimal TMD exert a more effectively act to transmission tower. Statistic shows the vibration decreasing ratio varies from $12.9 \%$ to $27.2 \%$ along the height of tower.

\section{CONCLUSIONS}

This paper investigates the optimal parameter of tuned mass damper and the responses of transmission tower-line system with and without optimal TMD under wind excitations. Based on theoretical analysis and numerical simulation results obtained, the following conclusions are drawn:

(1) The optimization of parameters of tuned mass damper, the stiffness and damping is rational and feasible.

(2) Using finite element software SAP2000, the threedimension finite model of optimal tuned mass damper and the transmission tower-line system can be successfully carried out.

(3) The transmission tower-line system with optimal TMD can decrease the structural responses, comparing to that without control. The results show that, at any moment of wind response time history, the optimal TMD can effectively reduce wind vibration, which have great significance for real construction and practical engineering application.

The effect of the optimal tuned mass damper for vibration control of transmission tower-line system with different mass ratio and in different directions should be investigated in further study.

\section{CONFLICT OF INTEREST}

The authors confirm that this article content has no conflicts of interest.

\section{ACKNOWLEDGEMENTS}

This work is financially supported by Ph.D. Programs Foundation of Ministry of Education of China project under grant No. 20120131120036, Shandong Provincial Natural Science Foundation of China under No. ZR2012EEQ005, and special fund from post-doctor innovation research program of shangdong province under grant No. 201203064. The supports for this research are greatly appreciated.

\section{REFERENCES}

[1] H. N. Li, and H. F. Bai, "State-of-the-art review on studies of disater resistance of high-voltage transmission tower-line systems”, China Civil Engineering Journal, vol. 40, pp. 39-46, 2007. (in Chinese)

[2] H. F. Bai, and H. N. Li, "Dynamic response of overhead transmission lines to oscillation caused by wind or rainfall loads", Power System Technology, vol. 33, pp. 36-40, 2009 (in Chinese)

[3] J. Zheng, and B. Chen, "Wind-induced vibration control of transmission tower-line system by using passive devices”, Journal of Wuhan University of Technology, vol. 29, pp. 80-92, 2007 (in Chinese)

[4] L. Tian, S. Jin, and Z. L Wang, "Rain-wind-induced vibration control for long span transmission tower", Applied Mechanics and Materials, vol. 160, pp. 240-244, 2012.

[5] T. T. Soong, and G. F. Dargush, Passive energy dissipation in systems structural engineering. John Wiley and Sons Press: New York, 1997.

[6] E. Simu, and R. H. Scanlan, Wind effects on structures: fundamentals and applications to design. John Wiley and Sons Press: New York, 1996.

[7] M. Shinozuka, C. B. Yun, and H. Seya. "Stochastic methods in wind engineering”, Journal of Wind Engineering and Industrial Aerodynamics, vol. 36, pp. 829-843, 1990. 